\title{
Change in Mechanical Properties by Titanium Addition in Aged Martensitic 18Ni-9Co-5Mo Alloy
}

\author{
Seyed Reza ELMI HOSSEINI ${ }^{11}$ and Hossein ARABI ${ }^{21}$ \\ 1) Department of Materials Science and Engineering, Faculty of Engineering, University of Sistan and Baluchestan (USB), \\ Zahedan, Iran. E-mail: Elmi@eng.usb.ac.ir \\ 2) Department of Metallurgy and Materials Engineering, Iran University of Science \& Technology (IUST), Narmak, Tehran, Iran.
}

(Received on April 13, 2011; accepted on August 24, 2011)

\begin{abstract}
Maraging steels are a group of materials with high strength and toughness. Titanium is the most widely used element in the above group, which helps to improve the mechanical properties by the formation of coherent $\mathrm{Ni}_{3} \mathrm{Ti}$ precipitates during the aging process. However, due to the high affinity of Ti to elements such as $\mathrm{C}, \mathrm{N}, \mathrm{S}$ and $\mathrm{O}$, harmful inclusions of these elements may form in the steels if due care is not exercised during the processing. The present research explores the effects of titanium, within the range of $1-$ 2 weight percent, on the mechanical properties of C300-grade maraging steels produced by vacuum arc remelting (VAR) technique. Then there is a discussion of the formation of deleterious titanium-rich inclusions and their effect on the mechanical properties of steel.
\end{abstract}

KEY WORDS: C300 maraging steels; vacuum arc remelting; mechanical properties; titanium.

\section{Introduction}

Maraging steels with the strength of approximately $2500 \mathrm{MPa}$ have high-impact resistance and suitable ductility. They can be used for various applications up to a temperature of $500^{\circ} \mathrm{C}$. $^{1)}$ They are composed of elements such as $\mathrm{Ni}, \mathrm{Co}, \mathrm{Mo}, \mathrm{Mn}, \mathrm{Ti}$, and a small amount of $\mathrm{C}$ and a few impurity elements. Due to their low carbon content, the strength of the martensitic structure of maraging steels is lower than those martensitic structures containing high carbon. However, their hardness and strength can be improved by aging. Decker ${ }^{1)}$ has reported that aging these types of steels causes the formation of very small coherent precipitates in the range of nanometer within their martensitic structure. This leads to an increase in the strength and hardness of the alloy. The most frequently reported precipitates are $\mathrm{Ni}_{3} \mathrm{Ti}, \mathrm{Fe}_{2} \mathrm{Mo}$, and $\mathrm{NiMn}$.

C300 maraging steel used in this research falls under the cobalt group of maraging steels having a strength of $2068 \mathrm{MPa}$. The typical chemical composition and the mechanical properties of this kind of steel are shown in Tables 1 and 2.2)

It is worth mentioning that the vacuum arc remelting (VAR) process is used when high-quality steels with uniform microstructure and high strength and toughness are required. Due to the use of metal mold in this process, usually a directional solidified structure is produced in VAR process. Furthermore, inclusions are usually broken because this process occurs in high arc temperature. After the process is completed, the broken inclusions can be dispersed in the matrix with more homogeneity. In addition, some of the inclusions may disintegrate chemically with the application
Table 1. Nominal composition of C300 maraging steel. ${ }^{2)}$

\begin{tabular}{cccccccc}
\hline Elements & $\mathrm{Ni}$ & $\mathrm{Mo}$ & $\mathrm{Co}$ & $\mathrm{Ti}$ & $\mathrm{Al}$ & $\mathrm{C}$ & $\mathrm{Fe}$ \\
\hline $\mathrm{wt} \%$ & 18 & 5.0 & 9.0 & 0.7 & 0.1 & $<0.03$ & Rem. \\
\hline
\end{tabular}

Table 2. Reported mechanical properties of C300 maraging steel. ${ }^{2)}$

\begin{tabular}{ccccccccc}
\hline U.T.S. & & Y.S. & & \multirow{2}{*}{$\begin{array}{c}\text { Elongation } \\
(\%)\end{array}$} & $\begin{array}{c}\text { R.A. } \\
(\%)\end{array}$ & \multicolumn{2}{c}{ Fracture toughness } \\
\cline { 1 - 1 } $\mathrm{MPa}$ & Ksi & MPa & Ksi & & MPa.m $^{1 / 2}$ & Ksi.in $^{1 / 2}$ \\
\hline 2047 & 297 & 2000 & 290 & 7 & 40 & 80 & 73 \\
\hline
\end{tabular}

of arc in high vacuum. ${ }^{3-5)}$ Thus, some of the solvent atomic gases and the gases resulting from the decomposition of inclusions can leave the melt when high vacuum is used. ${ }^{6-9)}$

\section{Experimental Procedure}

Three bars of C300 maraging steel weighing $6 \mathrm{~kg}$ were prepared in an Argon Induction Melting (AIM) furnace using electrolytic iron, electrolytic manganese, chromium, pure nickel shots, pure tungsten rods, ferromolybdenium, and ferrotitanium briquettes. Bars weighing $200 \mathrm{~g}$ were cut from the ingot and were remelted under argon gas in the water-cooled copper mold of a vacuum arc remelting furnace. Following that step, remelted bars were encapsulated in quartz tubes under argon gas after evacuation to $10^{-3} \mathrm{~Pa}$. Homogenization treatment was performed at $1200^{\circ} \mathrm{C}$ for $7.2 \mathrm{ks}$. Hot rolling to $60 \%$ thickness reduction was carried out, followed by water quenching. Solution annealing treatment at $820^{\circ} \mathrm{C}$ for $3.6 \mathrm{ks}$ in a vacuum furnace was followed by air-cooling in room temperature. Then, tensile, impact and hardness tests were carried out on the solution-annealed steel. 
Sheet-type tensile test pieces of $3 \mathrm{~mm}$ thickness, $6.3 \mathrm{~mm}$ width, and $30 \mathrm{~mm}$ gage length were cut according to ASTM E8. The tensile testing was carried out using an Instron universal tensile testing machine model 8502 at a displacement rate of $0.03 \mathrm{~mm} / \mathrm{s}$. Charpy tests were carried out on an instrumented impact machine of $300 \mathrm{~J}$ capacity and the absorbed energy was measured from the load time trace. The test was performed on $3 \times 10 \times 55 \mathrm{~mm}$ specimens according to ASTM A370. The dimensions of tensile and impact specimens used in this study are shown in Fig. 1. Hardness measurements were made using Vickers method of $294 \mathrm{~N}$ load. Data generated from tensile, hardness and impact tests were collected from four specimens tested. All the tests were conducted at room temperature. Mechanical behaviors were measured on longitudinal direction for the experimental samples. Finally, all specimens were aged at $500^{\circ} \mathrm{C}$ for a period of $10.8 \mathrm{ks}$. Aging was followed by quenching the specimens in water maintained at $25^{\circ} \mathrm{C}$.

The average chemical compositions of the before and after subjecting them to the VAR process bars -determined by the quantimetry technique- is shown in Table 3. The measured errors for all the elements fell within the range of

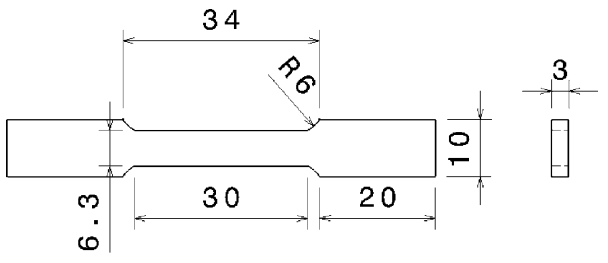

(a)

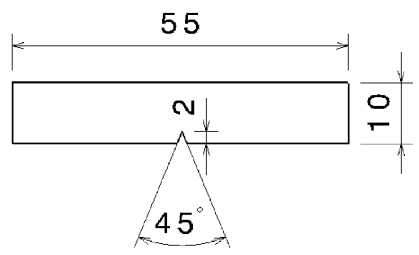

(b)

Fig. 1. Schematic diagrams showing the dimensions of (a) tensile and (b) impact specimens (Dimensions are according to $\mathrm{mm})$.
$0.10-0.35$ of the mean composition. The mean Ti content in each of the three cast bars were 1, 1.2, 1.5, 1.7 and $2 \mathrm{wt} \%$. The details of the VAR furnace used for melting and producing the bars is presented in Table 4.

After polishing, the specimens were examined through optical microscopy to calculate the volume fraction of inclusions. $400 \times$ Magnification was done to count the inclusions. In the magnification, at least 60 fields were used to calculate the volume fraction of inclusions.

\section{Results}

\subsection{The effect of Ti Addition on the Mechanical Prop- erties}

Results from the tensile tests conducted on the samples with different Ti contents are shown in Figs. 2(a) and 2(b), which respectively show the yield strength and the ultimate tensile strength vs. the function of titanium content. An appreciable increase in both Y.S. and U.T.S. was achieved up to $1.5 \mathrm{wt} \% \mathrm{Ti}$. However, only a marginal increase was observed in the samples with 1.7 and $2 \mathrm{wt} \%$ Ti. Figure 2(c) shows the variation of hardness vs. the function of Ti content, which is similar to the changes in the yield strength and the ultimate tensile strength shown in Figs. 2(a) and 2(b). Figs. 2(d) and 2(e), show respectively the reduction in area and the percentage elongation vs. the function of titanium content obtained from the tensile tests. A sharp decrease in ductility occurred at $1.5 \mathrm{wt} \%$ titanium, followed by a marginal decrease at 1.7 and $2 \mathrm{wt} \% \mathrm{Ti}$. The results obtained from the Charpy V-Notch test (C.V.N.) are shown in Fig. 2(f), where the absorbed energy of the specimens is plotted vs. the function of Ti content. A sharp drop in the absorbed energy is noticed in the specimen with $1.5 \mathrm{wt} \% \mathrm{Ti}$, followed by a marginal decrease at 1.7 and $2 \mathrm{wt} \% \mathrm{Ti}$. It is interesting to note that tensile ductility and impact energy attain a plateau after $1.5 \mathrm{wt} \% \mathrm{Ti}$.

\subsection{The Effect of Ti Content on the Volume Fraction of Inclusions}

It was observed that the mean volume fraction of inclusions in each bar is equal to their average area fraction of

Table 3. Melting conditions and compositions of the three bars used.

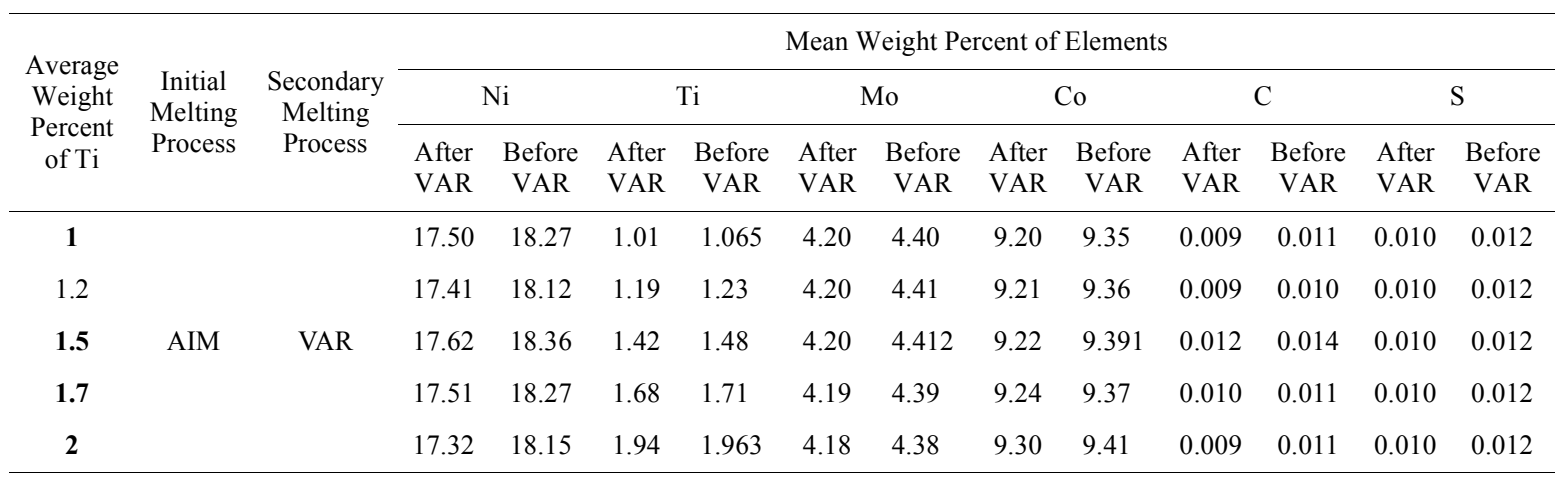

Table 4. The details of VAR furnace used.

\begin{tabular}{ccccccc}
\hline $\begin{array}{c}\text { VAR furnace } \\
\text { model }\end{array}$ & Used power & Electrode material & $\begin{array}{c}\text { Mold } \\
\text { material }\end{array}$ & $\begin{array}{c}\text { Mold } \\
\text { capacity }(\mathrm{g})\end{array}$ & $\begin{array}{c}\text { Vacuum level } \\
(\mathrm{Pa})\end{array}$ & $\begin{array}{c}\text { Arc temperature } \\
\left({ }^{\circ} \mathrm{C}\right)\end{array}$ \\
\hline ALD LK 6.45 & $600 \mathrm{~kW}$ & Tungsten (inconsumable) & Copper & 400 & $3 \pm 1 \times 10^{9}$ & $2500 \pm 20$ \\
\hline
\end{tabular}


ISIJ International, Vol. 52 (2012), No. 1

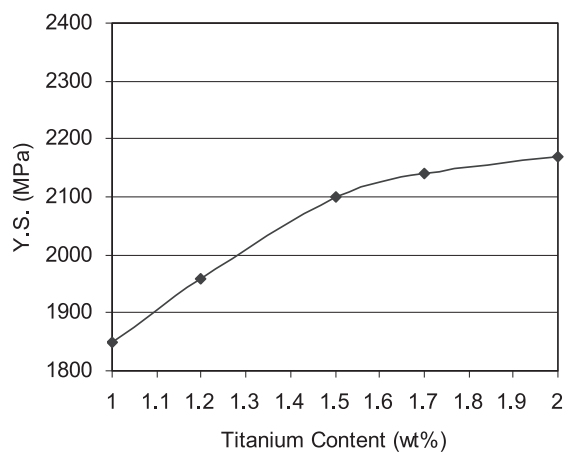

(a)

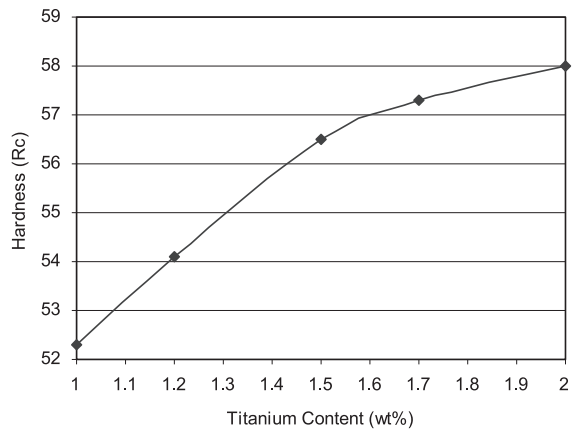

(c)

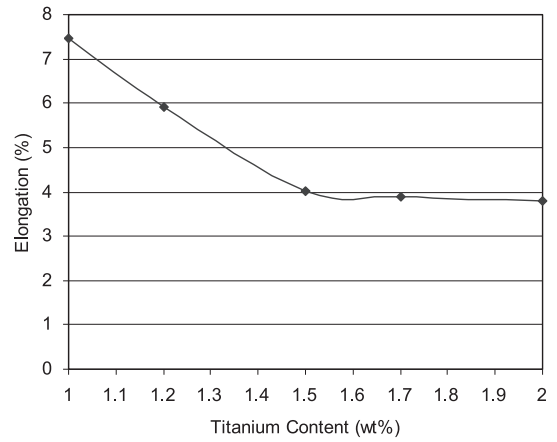

(e)

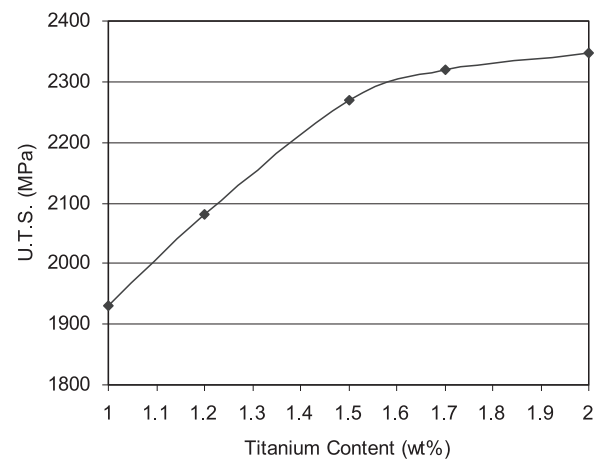

(b)

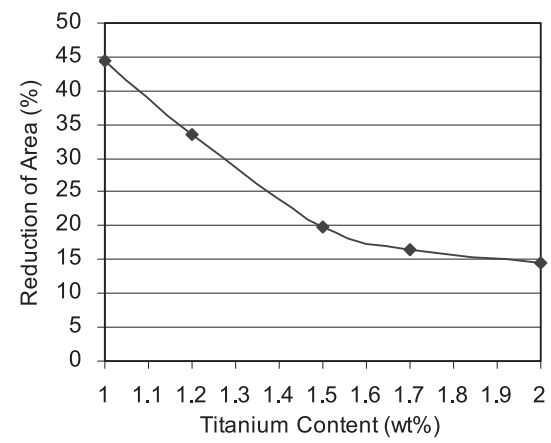

(d)

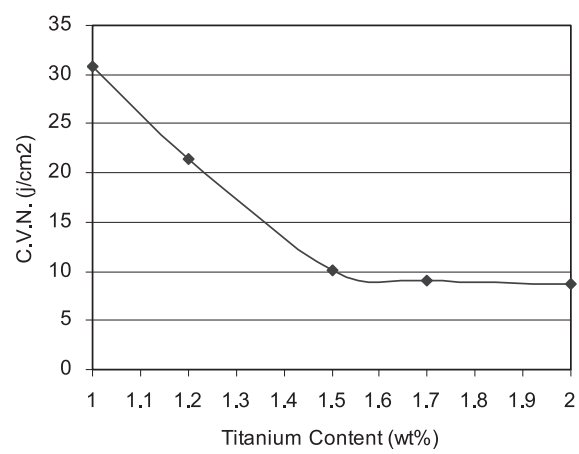

(f)

Fig. 2. Effect of Ti content on various mechanical properties of C300 maraging steel.

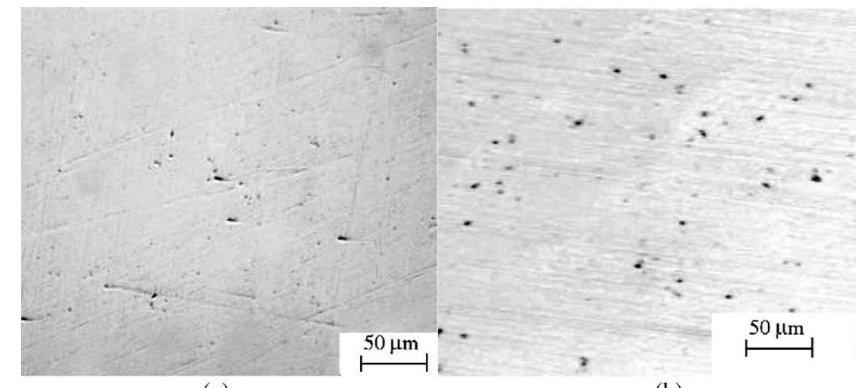

(a)

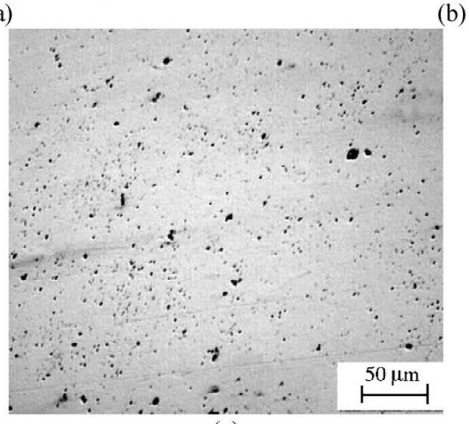

(c)

Fig. 3. Typical distribution of inclusions of maraging steel with (a) $1 \mathrm{wt} \% \mathrm{Ti}$, (b) $1.5 \mathrm{wt} \% \mathrm{Ti}$ and (c) $2 \mathrm{wt} \% \mathrm{Ti}$.

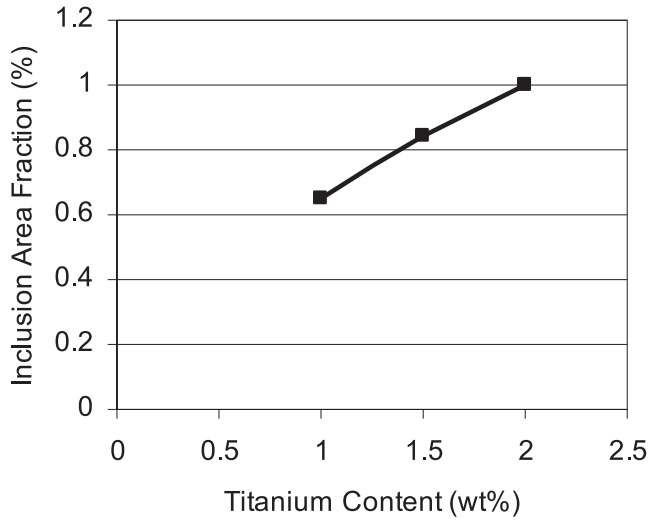

Fig. 4. Area fraction of inclusions as a function of Ti content.

inclusions. With the rise in the amount of $\mathrm{Ti}$, an increase in the size and the distribution of inclusions occued (Fig. 3). After calculating the percentage of the volume fraction of inclusions in the samples with different amounts of $\mathrm{Ti}$, it was found that the relationship between Ti content and the volume fraction of inclusions, irrespective of their kinds, was linear (see Fig. 4). 


\section{Discussion}

The addition of titanium in this type of steel caused the formation of small precipitates, which, in turn, increased the resistance of the matrix against the dislocation movement, hence an increase in strength and hardness. An experiment similar to this was done by Sinha et al. ${ }^{10)}$ and Vasudevan et al. ${ }^{11)}$ who said that small particles of $\mathrm{Ni}_{3} \mathrm{Ti}$ develop with the addition of $\mathrm{Ti}$ in this type of steel. The size of $\mathrm{Ni}_{3} \mathrm{Ti}$ precipitates is lower than $30 \mathrm{~nm}$. In addition, titanium has high affinity with oxygen and nitrogen. Increasing the Ti content causes the equilibrium at the melting temperature to move towards absorbing nitrogen and oxygen from the melt. Therefore, the area fraction of inclusions is increased.

When Ti content increases, the amount of $\mathrm{Ni}$ within the matrix does not increase simultaneously. Therefore, the formation rate of $\mathrm{Ni}_{3} \mathrm{Ti}$ precipitates decreases. It has also been claimed $^{2)}$ that $60 \%$ of the strength of maraging steel is due to its precipitates. Consequently, increasing Ti leads to a fall in the increasing rate of strength and hardness, while at the same time, it causes a rise in the strength and hardness. This is reflected by the decreasing rate in the hardness and strength up to $1.5 \mathrm{wt} \%$ of titanium and the sharp decreasing rate of hardness and strength when the Ti content exceeds $1.5 \mathrm{wt} \%$ [Figs. 2(a), 2(b) and 2(c))]. Regarding the reported formation of $\mathrm{Ni}_{3} \mathrm{Ti}$ precipitates as a fact, ${ }^{10,11)}$ the results presented in the previous section indicate that the rate of the formation of $\mathrm{Ni}_{3} \mathrm{Ti}$ precipitates was above that of inclusion formation for up to $1.5 \mathrm{wt} \%$ of Ti content. In addition, the rate of the formation of $\mathrm{Ni}_{3} \mathrm{Ti}$ precipitates was lower than that of inclusion formation when $\mathrm{Ti}$ content exceeded $1.5 \mathrm{wt} \%$. The increase of Ti led to a decrease in the reduction of area, elongation and impact energy since the strength of steel increased with the rise in $\mathrm{Ti}$, while the decreasing rate of these parameters reduced when Ti content exceeded $1.5 \mathrm{wt} \%$
Finally, There are some articles have been written about the effect of titanium on the mechanical properties of maraging steels, but there is a important difference between this study with these articles. The effect of Ti content more than $1 \mathrm{wt} \%$ have not been studied on mechanical properties. In maraging steels having Ti content lower than $1 \mathrm{wt} \%$, the relation between mechanical properties vs. amount of $\mathrm{Ti}$ is linear, whereas this relation is not linear in upper amounts of $1 \mathrm{wt} \%$ Ti.

\section{Conclusions}

(1) The rate of changes in mechanical properties due to the addition of $1-2 \mathrm{wt} \%$ Ti depends on the exact amount of Ti. When the amount of Ti exceeds $1.5 \mathrm{wt} \%$, the rate reduces substantially.

(2) It seems that $1.5 \mathrm{wt} \% \mathrm{Ti}$ within the composition of $\mathrm{C} 300$ steel is the upper limit of $\mathrm{Ti}$ content for maximum rates of changes in mechanical properties, such as strength, hardness, impact energy, and ductility.

\section{REFERENCES}

1) R. F. Decker: Source book on maraging steel, ASM International, Ohio, (1978), 44

2) ASM metals handbook, Vol. 1, ASM International, Ohio, (1991), 793.

3) M. J. Donachie and S. J. Donachie: Superalloys, a technical guide, ASM International, Ohio, (2002), 101

4) G. Ghosh: Secondary steelmaking, ASM International, Ohio, (2001), 55

5) S. R. Elmi Hoseini, H. Arabi and H. Razavizadeh: J. Metall. Eng., 9 (2006), 22

6) H. Shirazi: M. Sc. project, Tehran University, Iran, (2003), 77.

7) V. P. Kosukha, A. A. Pigenko and A. G. Papush: Stal, 20 (1975), 606.

8) S. R. Elmi Hoseini and H. Arabi: MJME, 4 (2010), 11.

9) S. R. Elmi Hoseini and H. Arabi: 4th Joint Conf. of Iranian Metallurgical Engineering Society and Iranian Foundry Society, Iran University of Science \& Technology, Tehran, (2010), 54.

10) P. P. Sinha and K. T. Tharian: Mater. Sci. Technol., 14 (1988), 1.

11) V. K. Vasudevan and S. J. Kim: Metall. Trans. A, 21 (1990), 2665 